\title{
СТАНОВЛЕНИЕ КОСМИЧЕСКИХ ИССЛЕДОВАНИЙ В КРЫМСКОЙ АСТРОФИЗИЧЕСКОЙ ОБСЕРВАТОРИИ АН СССР И ПЕРВЫЕ ЭКСПЕРИМЕНТАЛЬНЫЕ ДОСТИЖЕНИЯ Щербина А.Д.
}

Управление Российской Академии Наук по взаимодействию с научными организачиями Республики Крым и города федерального значения Севастополя, пгт Никита, г. Ялта,

Российская Федераиия, e-mail:aas175740@yandex.ru, aas@iki.rssi.ru

В статье на основе историко-научного анализа освещены этапы и ключевые моменты научноисследовательской работы ученых Крымской астрофизической обсерватории, которая осуществлялась в рамках эксперимента «ОСТ-1» на космической станции «Салют-4», «Интеркосмос-16». Указаны особенности работы солнечного телескопа для получения стигматичных ультрафиолетовых спектров от избранных участков солнечной поверхности, предназначенного для исследований в широком спектральном интервале от вакуумного ультрафиолета до инфракрасной области. Освещены достижения ученых КрАО АН СССР в рамках данного проекта, в частности успешное проведение экспериментов по нанесению новых отражающих слоев на оба зеркала телескопа. Определен вклад сотрудников исследовательского учреждения в развитие космической науки на территории Крымского полуострова на этапе ее становления.

Ключевые слова: космические исследования, Крымская астрофизическая обсерватория, эксперимент «ОСТ-1», космическая станция, солнечный телескоп.

\section{Введение}

В 60-х гг. XX ст. в связи со становлением нового направления исследований в астрономии - внеатмосферных исследований - в Крымской астрофизической обсерватории АН СССР (КрАО АН СССР) начала проводиться соответствующая научная работа. Техническое оснащение экспериментов вне атмосферы Земли было существенно ограничено, в основном, возможностями космических носителей астрофизических приборов. Искусственные спутники Земли (ИСЗ) либо ориентировались по одной оси вращения, либо вообще не были ориентированы. Задачи для таких экспериментов не отличались масштабностью: они сводились к измерению заданных величин с большим полем зрения, к определению минимальных и максимальных значений, к сравнению наблюдаемых значений с вычисленными на основе сведений о спектральном составе, численности и яркости звезд, туманностей в Галактике, данных о свечении зодиакального света.

\section{Результаты исследования}

Согласно с важнейшими изменениями в развитии космических исследований, проведенных отечественными учеными НИИ «КрАО», можно выделить следующие этапы: 
1 этап (1960-1974 гг.) - проведение внеатмосферных наблюдений с помощью отдельных оптических приборов, установленных на ИСЗ, автоматических станциях, космических аппаратах («Космос-213», «Космос-51», «Космос-166», «Прогноз-6» и др.);

2 этап (1975-1982 гг.) - изучение космических тел и процессов приборами, установленными на долговременных пилотируемых орбитальных научных станциях («Салют-4»);

3 этап (1983-1987 гг.) - осуществление исследований вне атмосферы Земли со специальной астрофизической космической станции, то есть так называемой беспилотной космической обсерватории («Астрон»);

4 этап (1988-2015 гг.) - изучение космических объектов с долговременной орбитальной астрофизической обсерватории («Спектр-УФ»).

Первой попыткой провести внеатмосферные исследования в КрАО АН СССР было создание в 1958 г. ракетного спектрометра. Эксперимент не состоялся из-за технических трудностей, не позволивших уложиться в отведенные сроки. В декабре 1959 г. коротковолновой спектрометр КДС-1, разработанный заведующим отделом экспериментальной астрофизики В.К. Прокофьевым, был запущен на 3-м кораблеспутнике и зарегистрировал спектр Солнца в узкой спектральной области 30.3-30.5 нм (линии Не II 30,4 нм) (Брунс, 2008). Прибор был рассчитан для работы на неориентированном спутнике и снабжен автономной системой двухкоординатной астроориентации на Солнце, которая, с помощью плоского поворотного зеркала, отражала свет на неподвижную входную щель спектрометра. В качестве диспергирующего элемента в спектрометре использовалась вогнутая дифракционная решетка, работавшая в схеме Роуланда. Сканирование спектра осуществлялось движением по кругу Роуланда выходной шели спектрометра, пропускавшей свет на расположенный за ней фотоприемник. В качестве фотоприемника использовался разработанный в Государственном оптическом институте им. С.И. Вавилова вторичный электронный умножитель открытого типа, не имевший ни стеклянной колбы, ни входного окна и использовавший при работе естественный вакуум космоса.

16 июня 1967 г. запущен модернизированный КДС-2 на ИСЗ «Космос-166», первой специализированной солнечной обсерватории для исследования ультрафиолетового и рентгеновского излучения Солнца. Научная аппаратура спутника состояла из рентгеновского фотометра, дифракционного ультрафиолетового спектрометра и рентгеновского гелиографа (Лебедев, 1968). В приборе КДС-2 был модернизирован спектрограф: расширен диапазон регистрации излучения Солнца 90.0110.0 нм. Была также разработана новая электронная система управления ориентацией. Запуск был произведен с полигона «Капустин Яр», около Волгограда (Отчеты...за 1967 г.). Прибор работал 20 суток и передал на Землю 1000 записей спектров.Этот материал позволил проследить динамику развития многих вспышек, определить поток и спектральный состав излучений, размеры и локализацию областей, где возникали вспышки, изучить физические условия в области вспышки и в прилегающих активных участках короны. Регистрация спектрометром линии ионизированного гелия дала информацию о состоянии солнечной атмосферы под вспышкой. Сотрудниками КрАО $\mathrm{AH}$ СССР обнаружено увеличение ультрафиолетового излучения с увеличением площади активных образований на Солнце. Результаты эксперимента представляли большой интерес для выяснения природы рентгеновских и оптических вспышек и возможности их прогнозирования.

В 1967 и 1968 гг. по инициативе и при активном участии Физического института АН СССР был произведен запуск первых советских спутников для исследования Солнца, «Космос-166» и «Космос-230». Специально для этого эксперимента в лаборатории КрАО АН СССР были разработаны и созданы рентгеновские гелиографы 
и фотометры оригинальной конструкции, позволившие получить более 1000 изображений Солнца в пяти спектральных диапазонах с угловым разрешением около 20 секунд. В ходе эксперимента были получены существенно новые данные о структуре рентгеновских вспышек, в частности впервые прослежена динамика их развития, а по заходу активной области за лимб оценена ее высота - порядка 20 тыс. км над фотосферой.

В этот же период были начаты первые эксперименты по получению спектров Солнца в коротковолновой области с помощью дифракционных решеток и брэгговских кристаллов. В ходе них была получена первая в мире фотография рентгеновского спектра в области длин волн короче $9.5 \AA$, а всего были зарегистрированы спектры до длины волны $1.7 \AA$ и достигнуто уникальное разрешение $\lambda / \Delta \lambda \sim 104$. Это позволило уточнить обилия элементов в атмосфере Солнца, а также обнаружить макроскопические движения в корональных конденсациях со скоростью по лучу зрения до 100 км/сек. В спектрах вспышек были обнаружены линии ионов MgXI, FeIX, FeX и FeXVII.

Во второй половине XX ст. неизученная ультрафиолетовая область солнечного спектра считалась наиболее информативной для исследования физического состояния верхних слоев атмосферы Солнца. Для разработки данного вопроса был создан орбитальный солнечный телескоп (ОСТ-1) с высоким пространственным разрешением. Наиболее благоприятным временем для исследования процессов на Солнце является пик его активности. Поскольку таковой приходился на 1969-1970 гг., заявка от сотрудников КрАО АН СССР на проведение эксперимента «ОСТ-1» была подана в вышеуказанный период. Согласно данным репрезентативных документов, удачному проведению исследования предшествовал ряд попыток.

В 1975 г. руководство над экспериментом «ОСТ-1» было возложено на Н.В. Стешенко, конструктором назначен А.В. Брунс. Разработчики ОСТ-1 решили основные из перечисленных проблем в конструкции телескопа. Все механические и оптические части телескопа спроектированы и сделаны в КрАО АН СССР, за исключением решеток. При длине телескопа более 3 м его установка не вызывала затруднений благодаря основной конструктивной идее. Система подразделялась на отдельные блоки, включающие в себя от одного до нескольких оптических элементов. Полная оптическая схема комплекса создавалась при соответствующем расположении блоков на поверхности отсека научной аппаратуры, корпус которого фактически выполнял роль несущей конструкции. Использование для точного наведения поворачивающегося плоского зеркала дало возможность установить телескоп на орбитальную станцию, имеющую точность ориентации $1^{\circ}$. При этом вся система телескопа располагалась неподвижно относительно корпуса станции, что позволило решить проблему доставки фотокассет из открытого космоса.

Среди особых достижений разработчиков ОСТ-1 следует отметить уникальное технологическое решение. Отечественными учеными впервые в мире реализован метод нанесения свежих покрытий в космосе специально сконструированными установками для термомолекулярного напыления алюминия с целью предотвратить влияние контаминации на отражающие свойства зеркал. Состояние оптических элементов на космическом телескопе определялось степенью образования налета за счет конденсации на них различных веществ, входящих в микроатмосферу космического аппарата. Поэтому учеными КрАО АН СССР было принято решение разработать и установить на ОСТ-1 устройство для термомолекулярного нанесения на зеркала новых отражающих слоев в процессе их эксплуатации на борту орбитальной космической станции. Помимо сотрудников обсерватории изъявил желание руководить проектом В.В. Бенюх. Заместитель директора по научной работе Н.В. Стешенко объявил конкурс проектов, который завершился явным преимуществом основного варианта. В 
соответствии с ним проектом была изготовлена бортовая установка для термомолекулярного напыления алюминия. Каждое зеркало ОСТ-1 было снабжено испарителем алюминия, управляемым с пульта управления бортинженера. Это позволило примерно в 12 раз увеличить отражение от щечек щели, которые не имели отдельной защиты во время вывода корабля на орбиту. Космонавтами первой экспедиции было произведено напыление алюминия на главное зеркало, второй экспедиции - на следящее зеркало телескопа. Как показали измерения, отражающие свойства слоя алюминия, напыленного в космосе, оказались практически такими же, как у многослойных покрытий, выполненных в лаборатории. В то же время на зеркалах телескопа сотрудниками КрАО АН СССР не зафиксировано преимущество в коэффициенте отражения в ультрафиолетовой области спектра из-за быстрого окисления алюминиевого покрытия атомами и попами кислорода, присутствующими в малых количествах вокруг корабля.

Проведение астрофизического эксперимента «ОСТ-1» было осложнено минимальной солнечной активностью. На поверхности Солнца учеными наблюдалось малое количество активных образований. Еще более редкими были такие явления как вспышки. За проведение эксперимента и получение весомых результатов в области астрофизики присуждена правительственная награда - Орден Трудового Красного Знамени. «За достигнутые успехи в развитии народного хозяйства» два участника эксперимента награждены Золотыми, один 1 серебряной и десять - бронзовыми медалями ВДНХ. Эксперимент «ОСТ-1» значился как главный в программе орбитальной космической станции «Салют-4», и назывался Астрофизический эксперимент №1. По «Табелю о рангах» подобные, успешно проведенные основные эксперименты космических запусков отмечались Государственной премией (Брунс, 1999). Парадоксально, но Комитет по делам изобретений и открытий не выявил в эксперименте элементы новизны. Универсальность «ОСТ-1», заключающаяся в размещении на станции «Салют-4» блоков телескопа на поверхности станции без собственной несущей конструкции, не была признана.

Тем не менее ученые КрАО АН СССР внесли большой вклад в развитие космической науки на территории Крымского полуострова. Ими был разработан и сконструирован крупнейший в мире управляемый космонавтами солнечный телескоп с фокусным расстоянием 2.5 м и рабочей аппаратурой $490 \mathrm{~cm}^{2}$, работавший в широком спектральном интервале от вакуумного ультрафиолета до инфракрасной области. Уникальный астрофизический комплекс «ОСТ-1» отличался от всей созданной ранее оптической аппаратуры для проведения внеатмосферных экспериментов. Он не имел собственной единой механической конструкции, состоял из ряда отдельных блоков, содержащих логически законченные части оптической системы. В конструкцию Н $\alpha-$ камеры был впервые внедрен интерференционно-поляризационный фильтр, снабженный оригинальной системой терморегулирования и обеспечивающий при длине волны фильтра $\lambda=656.3$ нм полосу 0.05 нм, полноценно функционировавший на орбите ИСЗ. Низкоаберрационный ультрафиолетовый спектрограф с двойной монохроматизацией в сочетании с ОСТ-1, дававшим высококачественные изображения Солнца, впервые дал возможность получить стигматичные короткие ультрафиолетовые спектры, в которых участки спектральных линий по высоте спектра принадлежали соответствующим точкам изображения, передаваемым входной щелью.

Запуск астрофизического комплекса «ОСТ-1» ознаменовал начало широкого освоения нового спектрального диапазона в прикладной науке, а именно далекого ультрафиолета, включая вакуумный. Изучение сотрудниками КрАО АН СССР ультрафиолетовых спектров солнечных образований позволило дать объективную оценку физическим условиям в последних на уровне верхней хромосферы и переход $\neg$ ной зоны между хромосферой и короной. В системе был впервые применен 
теневой датчик ориентации, позволивший существенно упростить механическую часть системы и тем самым повысить ее общую надежность. К достижениям ученых КрАО АН СССР можно отнести успешное проведение экспериментов по нанесению новых отражающих слоев на оба зеркала телескопа. Космонавтами первой экспедиции О.О. Губаревым и Г.И. Гречко нанесено новое отражающее покрытие на главное зеркало, а космонавтами второй - П.И. Климуком и В.И. Севастьяновым алюминировано следящее зеркало.

По результатам эксперимента «ОСТ-1» сотрудниками КрАО АН СССР создан каталог фотографий спектров, опубликованы более 12 печатных работ в отечественных и зарубежных журналах, сделано шесть докладов на Международных симпозиумах и конференциях и четыре сообщения на внутрисоюзных конференциях (Брунс, 2008). Удачное проведение эксперимента «ОСТ-1» обусловило начало работ над проектом «Астрон» под руководством А.А. Боярчука.

Изучение солнечной короны с помощью ультрафиолетового спектрометра были начаты в КрАО АН СССР в 1974 г. После неудачного эксперимента с «Салютом-3» сотрудники обсерватории начали подготовку к первому в практике научного учреждения международному советско-шведскому космическому эксперименту. Исследовательская работа проводилась по программе «Интеркосмос». Научными представителями от СССР были И.А. Житник (Физический институт АН) и А.В. Брунс, В.К. Прокофьев (КрАО АН СССР), руководителем от Швеции назначен астрофизик Ян Олафф Стенфло. Эксперимент за границей осуществляла корпорация Swedish Space Corporation, разработкой прибора занимались фирмы Jungner Instrument AB и SAABSCANIA.

Основной задачей исследовательского проекта было изучение магнитного поля Солнца путем измерения его влияния на линейную поляризацию излучения на солнечном лимбе. Для проведения наблюдений в диапазоне длин волн 120-150 нм учеными КрАО АН СССР разработан прибор спектрометр-поляриметр, который устанавливался на спутник «Интеркосмос-16», запущенный 26 июля 1976 г. (Отчеты...за 1976 г.).

Внеатмосферный эксперимент «Интеркосмос-16», осуществленный на последнем аппарате в серии малых спутников, позволил получить астрофизикам данные о спектрах высокого разрешения рентгеновского и ультрафиолетового излучения Солнца в период минимума солнечной активности, что дало определенное представление о строении солнечной атмосферы. Также отечественными учеными изучены динамика, спектр и поляризация рентгеновского излучения Солнца. Проведенные наблюдения дали необходимый материал для решения проблемных вопросов в астрофизике, подготовив основу для осуществления ряда фундаментальных космических исследований КрАО АН СССР.

\section{Выводы}

Установлено, что на протяжении более чем 50 лет учеными НИИ «КрАО» проведены уникальные эксперименты по изучению Солнца, его структур и образований с помощью специальных астрофизических методов.

Полученные результаты исследований представляли большой интерес для выяснения природы рентгеновских и оптических вспышек и возможности их прогнозирования. 


\section{Список литературы}

1. Брунс A.B. Как это было. Орбитальный солнечный телескоп Крымской астрофизической обсерватории. - Научный, 1999. - 99 с.

2. Брунс A.B. Как это было: внеатмосферные исследования солнца Крымской астрофизической обсерватории // Из истории Крымской астрофизической обсерватории. Сборник рассказов. - Симферополь: Издательский дом «ЧерноморПРЕСС», 2008. - $128 \mathrm{c}$.

3. Лебедев Л. Советские космические исследования в 1967 г. // Ежегодник большой советской энциклопедии. - М., 1968. - Вып. 12. - 621 с.

4. Отчеть учреждений отделения по научной $и$ научно-организационной деятельности за 1967 г. // АРАН. Ф. 1948. Оп. 2. Ед. хр. 2. 181 л.

5. Отчеть учреждений отделения по научной $и$ научно-организационной деятельности за 1976 г. // АРАН. Ф. 1948. Оп. 2. Ед. хр. 16. 353 л.

6. Справка Крымской астрофизической обсерватории об эффрективности международных научных связей за период 1966-1970 г2. // Архив российской академии наук (далее АРАН). Ф. 472. Оп. 1. Ед. хр. 738. 14 л.

\section{THE FORMATION OF SPACE RESEARCH IN THE CRIMEAN ASTROPHYSICAL OBSERVATORY OF THE USSR AS AND THE FIRST EXPERIMENTAL ACHIEVEMENTS \\ Shcherbina A.D.}

Administration of the Russian Academy of Sciences for Interaction with Scientific Organizations of the Republic of Crimea and the City of Federal Significance in Sevastopol, Nikita, Yalta, Russian Federation,

e-mail:aas175740@yandex.ru, aas@iki.rssi.ru

On the basis of historical and scientific analysis highlights the stages and key points for the research of the scientists of the Crimean Astrophysical Observatory, that carried out within the experiment "OST1 " on the Orbital Station "Salyut", "Intercosmos-16". Features of operation of the solar telescope for the receiving the stigmatic ultra-violet ranges from the chosen sites of a solar surface intended for researches in a wide spectral interval from a vacuum ultraviolet to infrared area are specified. Achievements of scientific of the Crimean astrophysical observatory of Academy of Sciences of the USSR within this project, in particular successful carrying out experiments on drawing the new reflecting layers on both mirrors of the telescope are lit. The contribution of staff of research institution to development of space science in the territory of the Crimean peninsula is defined at the stage of its development.

Key words: space research, Crimean Astrophysical Observatory, OST-1 experiment, space station, solar telescope.

Поступила в редакциюю 11.03.2018 г. 